\title{
Immune-Related Comorbidities in Childhood-Onset Obsessive Compulsive Disorder: Lifetime Prevalence in the Obsessive Compulsive Disorder Collaborative Genetics Association Study
}

\author{
Clara Westwell-Roper, MD, PhD, ${ }^{1}$ Kyle A. Williams, MD, PhD, ${ }^{2}$ Jack Samuels, $\mathrm{PhD},{ }^{3}$ \\ O. Joseph Bienvenu, MD, PhD, ${ }^{3}$ Bernadette Cullen, MD, ${ }^{3}$ Fernando S. Goes, MD, ${ }^{3}$ \\ Marco A. Grados, MD, MPH, ${ }^{3}$ Daniel Geller, MD, ${ }^{2}$ Benjamin D. Greenberg, MD, PhD, ${ }^{4}$ \\ James A. Knowles, MD, PhD, ${ }^{5}$ Janice Krasnow, PhD, ${ }^{3}$ Nicole C. McLaughlin, PhD, ${ }^{4}$ Paul Nestadt, MD, ${ }^{3}$ \\ Yin-Yao Shugart, PhD, ${ }^{6}$ Gerald Nestadt, MD, MPH, ${ }^{3}$ and S. Evelyn Stewart, MD ${ }^{1}$
}

\begin{abstract}
Objective: To evaluate the lifetime prevalence of infectious, inflammatory, and autoimmune disorders in a multisite study of probands with childhood-onset obsessive compulsive disorder (OCD) and their first-degree relatives.

Methods: Medical questionnaires were completed by 1401 probands and 1045 first-degree relatives in the OCD Collaborative Genetics Association Study. Lifetime prevalence of immune-related diseases was compared with the highest available population estimate and reported as a point estimate with $95 \%$ adjusted Wald interval. Worst-episode OCD severity and symptom dimensions were assessed with the Yale-Brown Obsessive Compulsive Scale (YBOCS) and Symptom Checklist (YBOCS-CL).

Results: Probands reported higher-than-expected prevalence of scarlet fever $(4.0[3.1-5.2] \%$ vs. $1.0 \%-2.0 \%, z=1.491$, $p<0.001, n=1389)$, encephalitis or meningitis $(1.4[0.9-2.1] \%$ vs. $0.1 \%-0.4 \%, z=5.913, p<0.001, n=1393)$, rheumatoid arthritis $(1.1[0.6-2.0] \%$ vs. $0.2 \%-0.4 \%, z=3.416, p<0.001, n=949)$ and rheumatic fever $(0.6[0.3-1.2] \%$ vs. $0.1 \%-0.2 \%$, $z=3.338, p<0.001, n=1390$ ), but not systemic lupus erythematosus, diabetes, asthma, multiple sclerosis, psoriasis, or inflammatory bowel disease. First-degree relatives reported similarly elevated rates of scarlet fever, rheumatic fever, and encephalitis or meningitis independent of OCD status. There was no association between worst-episode severity and immunerelated comorbidities, although probands reporting frequent ear or throat infections had increased severity of cleaning-/ contamination-related symptoms (mean factor score $2.5 \pm 0.9$ vs. $2.3 \pm 1.0, t=3.183, p=0.002, n=822$ ).

Conclusion: These data suggest high rates of streptococcal-related and other immune-mediated diseases in patients with childhood-onset OCD and are consistent with epidemiological studies in adults noting familial clustering. Limitations include potential reporting bias and absence of a control group, underscoring the need for further prospective studies characterizing medical and psychiatric disease clusters and their interactions in children. Such studies may ultimately improve our understanding of OCD pathogenesis and aid in the development of adjunctive immune-modulating therapeutic strategies.
\end{abstract}

Keywords: obsessive compulsive disorder, childhood-onset, comorbidity, immune system diseases, autoimmune diseases, communicable diseases, inflammation

\footnotetext{
${ }^{1}$ Department of Psychiatry, Faculty of Medicine, British Columbia Children's Hospital, University of British Columbia, Vancouver, Canada.

${ }^{2}$ Department of Psychiatry, Harvard Medical School, Massachusetts General Hospital, Boston, Massachusetts.

${ }^{3}$ Department of Psychiatry and Behavioral Sciences, Johns Hopkins University School of Medicine, Baltimore, Maryland.

${ }^{4}$ Department of Psychiatry and Human Behavior, Brown Medical School, Butler Hospital, Providence, Rhode Island.

${ }^{5}$ Department of Psychiatry, University of Southern California School of Medicine, Los Angeles, California.

${ }^{6}$ Unit of Statistical Genomics, Division of Intramural Research, National Institute of Mental Health, Bethesda, Maryland.

Funding: The OCGAS is a collaborative research study and was funded by the following NIMH Grant Numbers: MH071507, MH079489, MH079487, MH079488, and MH079494. S.E.S. is supported by a Michael Smith Foundation Scholar Award and a CIHR operating grant and supervised the specific analyses included in this article.

(C) Clara Westwell-Roper et al. 2019; Published by Mary Ann Liebert, Inc. This Open Access article is distributed under the terms of the Creative Commons License (http://creativecommons.org/licenses/by/4.0), which permits unrestricted use, distribution, and reproduction in any medium, provided the original work is properly cited.
} 


\section{Introduction}

O BSESSIVE COMPULSIVE DISORDER (OCD) affects 1\%-3\% of children worldwide and causes significant distress for patients and families (Hollander et al. 2016). Despite effective cognitive behavioral therapy and pharmacotherapy, many patients experience a chronic, episodic course with long-term functional impairment (Stewart et al. 2004; Mancebo et al. 2014).

While the underlying pathophysiological mechanisms remain to be elucidated, meta-analyses of family studies suggest heritability may be as high as 50\%-60\% in childhood-onset OCD (Nestadt et al. 2000; Mataix-Cols et al. 2013). Genetic association studies have implicated single nucleotide polymorphisms in genes involved in glutaminergic transmission as well as immune function (den Braber et al. 2016), although none has yet reached genomewide significance (Stewart et al. 2013; Taylor 2013; Mattheisen et al. 2015; International Obsessive Compulsive Disorder Foundation Genetics Collaborative [IOCDF-GC] and OCD Collaborative Genetics Association Studies [OCGAS] 2018).

Increasing evidence suggests a potential role for the immune system in OCD pathogenesis. Children with sudden onset of OCD and/or motor tics and evidence of recent streptococcal infection may meet criteria for pediatric autoimmune neuropsychiatric disorder associated with streptococcal infections (PANDAS) (Williams and Swedo 2015). Early studies suggested that this subset of patients may develop postinfectious immune-mediated damage to the basal ganglia, as described for Syndenham's chorea, a neuropsychiatric complication of rheumatic fever (RF) (Williams and Swedo 2015).

A potential role for infection as a trigger for neuropsychiatric symptoms is supported by epidemiological evidence of an association between throat infections and mental disorders, in particular OCD (Orlovska et al. 2017). Although controversial, definitive evidence for causative pathogenic autoantibodies in humans is lacking (Dale et al. 2005; Morer et al. 2008) and PANDAStogether with pediatric acute-onset neuropsychiatric syndrome (PANS) - may account for as few as 5\% of children attending some general pediatric OCD outpatient clinics (Jaspers-Fayer et al. 2017).

Data from studies in patients with "classic" OCD also suggest an association with aberrant innate immune activation. This includes altered levels of systemic cytokines, such as tumor necrosis factor- $\alpha$ and interlelukin- $1 \beta$ (Gray and Bloch 2012; Mitchell and Goldstein 2014; Rao et al. 2015; Simsek et al. 2016) as well as lower-than-expected immunoglobulin titers (Kawikova et al. 2010; Williams 2016; Calaprice et al. 2017), including immunoglobulin A (IgA), which provides protection at mucosal surfaces and can be produced through $\mathrm{T}$ cell-independent mechanisms (Macpherson et al. 2011). Moreover, a recent positron emission tomography imaging study in adults with OCD—many with childhood-onsetshowed increased volume of translocator protein-18 (TSPO) distribution in cortico-striato-thalamo-cortical circuits, implicating widespread microglial activation (Attwells et al. 2017). Further support for a potential causative or perpetuating role of inflammation due to abnormal innate immune cell activity was provided by a double-blind, placebo-controlled randomized controlled trial of 50 adult outpatients with moderate-to-severe OCD that found modest symptom improvement with the nonsteroidal antiinflammatory drug (NSAID) celecoxib as an adjuvant to fluvoxamine (Shalbafan et al. 2015).

Patients with autoimmune disorders such as systemic lupus erythematosus (SLE) and RF - and in some cases, their first-degree relatives - have higher rates of comorbid OCD and anxiety disorders compared with the general population (Slattery et al. 2004;
Hounie et al. 2007). A recent large birth cohort study based on Swedish National Register data also suggested increased rates of multiple autoimmune diseases among adults with OCD as well as their first-degree relatives, including inflammatory bowel disease (IBD), Hashimoto's thyroiditis, celiac disease, psoriasis, type 1 diabetes, idiopathic thrombocytopenic purpura, Sjögren's syndrome, and Guillan-Barré syndrome in addition to scarlet fever (Mataix-Cols et al. 2017).

Potential mechanisms leading to familial associations between immune-mediated diseases and OCD include dual genetic and environmental susceptibility and exposure to maternal antibodies (Vincent et al. 2003) or plasma cytokines (Golan et al. 2005) leading to altered perinatal brain development. While the current PANS consensus guidelines recommend clinicians take a thorough personal and family history of autoimmune and infectious diseases in children with OCD (Chang et al. 2015), little is known about the prevalence of these conditions in this population (Perez-Vigil et al. 2016).

Previous studies have implicated frequent infections, low immunoglobulin titers, and higher rates of atopy among OCD probands together with increased prevalence of autoimmune diseases among their mothers (Murphy et al. 2010; Stagi et al. 2014; Yuce et al. 2014; Frankovich et al. 2015; Calaprice et al. 2017) (Supplementary Table S1). However, these reports are limited by the absence of control or population data, measurement of hematologic parameters only in the setting of acute symptom flares, restriction to PANS or PANDAS subtypes rather than heterogeneous or adult OCD samples, or small sample sizes. This study examined the prevalence of self-reported immune-mediated illnesses in patients with childhood-onset OCD not selected for PANDAS or PANS and compared these with expected ranges derived from a review of published population estimates. We hypothesized that shared genetic and environmental predisposing factors may contribute to increased rates of immune-related diseases among heterogeneous patients with childhood-onset OCD.

\section{Methods}

\section{Study cohort}

The multisite OCGAS comprised patients with OCD onset before the age of 18, recruited between 2007 and 2012 (Mattheisen et al. 2015). Study design and methods have been described previously (Samuels et al. 2006). A total of 1065 families were included; of these, 621 families were recruited and assessed specifically for this study at one of the five participating recruitment sites or the National Institute of Mental Health (NIMH), whereas 444 families had been evaluated previously in an earlier study at one of the collaborating sites. The complete sample comprised 460 trios (an affected proband and both parents), 155 pedigrees with a proband and an unaffected sibling, 450 families with another structure, and an additional 192 singleton probands.

Inclusion criteria were as follows: (1) Diagnostic and Statistical Manual of Mental Disorders, 4th ed (DSM-IV, American Psychiatric Association 1994) OCD diagnosis as established by standardized interview by a psychiatrist or clinical psychologist using the Structured Clinical Interview for DSM-IV with additional symptom and diagnostic information as previously described (Mattheisen et al. 2015), and (2) onset of obsessions and/or compulsions before age 18 .

Exclusion criteria were as follows: (1) subjects with schizophrenia, severe intellectual disability, or another condition preventing 
evaluation; (2) Tourette disorder without OCD; (3) OCD-like symptoms occurring exclusively in the context of depression; and (4) previous diagnosis of brain pathology, including brain tumors, Huntington's disease, Parkinson's disease, or Alzheimer's disease. Final diagnostic status was assigned based on the consensus of two psychiatrists or psychologists reviewing the case independently followed by review by one of five consensus psychiatrists as described previously (Samuels et al. 2006). Probands with a diagnosis of "probable" or "definite" OCD were included.

Study protocols were approved by the Institutional Review Boards at all participating sites. All participants provided written informed consent.

\section{Study measures and instruments}

OCD assessment was performed as described previously and adapted from the Schedule for Affective Disorders and Schizophrenia-Lifetime Version (SADS-LA-R) (Samuels et al. 2006). The Structured Clinical Interview for DSM-IV Axis I Disorders (SCID-I) is a semistructured interview for making major DSM-IV Axis I diagnoses and was used in assessment of psychiatric comorbidities (First et al. 2002).

OCD severity for the worst episode was assessed using the YaleBrown Obsessive Compulsive Scale (YBOCS) (Goodman et al. 1989). Severity ratings for specific symptom dimensions were determined as described previously using the YBOCS Symptom Checklist (YBOCS-CL) to score each of four factors: forbidden thoughts (aggressive, religious, and sexual obsession categories), symmetry (symmetry obsessions, checking, counting, ordering, and repeating compulsion categories), cleaning (contamination, somatic obsessions, and cleaning compulsion categories), and hoarding (hoarding obsession/compulsion categories) (Bloch et al. 2008).

Medical comorbidities were assessed by self report using a standard medical questionnaire (Supplementary Data). Selected chronic comorbidities specified a requirement for physician diagnosis, whereas acute or episodic conditions did not. Questionnaires assessing personal and family history of selected infectious, autoimmune, and inflammatory conditions were completed by probands and a subset of the questionnaire was also completed by first-degree relatives (Supplementary Data). These included (1) self-reported history of encephalitis or meningitis, frequent ear/throat infections (frequency not defined), scarlet fever, RF, and rheumatic heart disease in both probands and first-degree relatives; and (2) selfreported physician diagnosis of rheumatoid arthritis (RA), SLE, multiple sclerosis (MS), diabetes, asthma, psoriasis, ulcerative colitis, Crohn's disease, and Sydenham's chorea in probands only. No additional follow-up or verification of reported comorbidities was performed.

\section{Estimation of population prevalence}

To determine expected population prevalence of the immunerelated comorbidities included in the OCGAS medical questionnaire, a review of United States data was carried out using PubMed and Medline databases and annual reports published by the Centers for Disease Control and Prevention. Keywords and subject headings were used to identify studies of prevalence or incidence. Both population-based cross-sectional and cohort studies were included, with data based on self-report surveys, where available. When national data were unavailable, North American data were used. Broad ranges were used to include all frequencies and confidence intervals described in identified reports. Where incidence only was available, prevalence was determined by multiplying by the co- hort's mean age, 27.8 years. These conservative lifetime prevalence values derived from incidence are therefore likely to be overestimates. Where indicated in Supplementary Table S2, under- or nonreporting of diseases limited the utility of available data.

\section{Data analyses}

Statistical analyses were conducted using SPSS (Version 24, IBM Corporation). Prevalence was reported as an exact point estimate and 95\% adjusted Wald interval (Agresti and Coull 1998). The valid percent was reported if data were missing, determined by excluding cases with either no response or with responses reported as "unsure." Differences between means for continuous variables were analyzed with a two-sided student's $t$-test or Welch's $t$-test (Welch 1947) as indicated by the results of Levene's test for equal variances (Levene 1960). One-sample $z$-tests with binomial $p$ values were used to compare prevalence estimates with the maximum population estimate based on literature review. Given low frequencies for some conditions, differences among dichotomous categorical variables were analyzed with a two-sided Fisher's exact test. Pearson's chi-squared test was used to compare frequencies for nominal variables with two or more categories. Correction for multiple comparisons was applied as indicated using the Bonferonni correction with $\alpha=0.05$ for the indicated number ( $n$ ) of tests (Benjamini and Hochberg 1995). Continuous variables are reported as mean \pm standard deviation with $95 \%$ confidence intervals in square brackets.

\section{Results}

\section{Participant demographics}

Demographic information is shown in Table 1. A total of 1401 probands met inclusion criteria. Probands had an average age of $27.8 \pm 14.1$ years (median 25 years) with a history of symptom onset at $7.7 \pm 3.5$ years and diagnosis at $10.1 \pm 3.7$ years. One-third (33\%) were age 18 or under at the time of assessment. Approximately half (56\%) were female and $91 \%$ identified as Caucasian or White. At the time of assessment, females were on average older than males [mean age $29.7 \pm 14.3$ vs. $25.4 \pm 13.4$ years, $t(1399)=-5.741$, $p<0.001, n=1401]$ and had experienced OCD symptom onset at a younger age $[7.5 \pm 3.3$ vs. $8.1 \pm 3.7$ years, $t(1239)=3.369, p=0.001$, $n=1398]$.

Mean YBOCS score for the worst episode was 29 \pm 6.3 , consistent with previous reports (Chen et al. 2017). Most participants (81\%) had worst-episode YBOCS scores in the severe-to-extreme range of 24 and above. Two participants had scores in the subclinical range (0-7); omission of these individuals did not affect our reported results.

\section{Lifetime prevalence of immune-related diseases}

Self-reported lifetime prevalence of immune-related comorbidities included in the medical questionnaire is shown in Table 2. There were no cases of rheumatic heart disease. The prevalence of Sydenham's chorea and MS (one and two cases, respectively) was not significantly different from zero. Lifetime prevalence of SLE, type 1 diabetes (based on insulin dependence under age 40), asthma, psoriasis, and IBD was within the range expected based on population data (reviewed in Supplementary Table S2). Higherthan-expected prevalence was reported for encephalitis or meningitis $(1.4[0.9-2.1] \%$ vs. $0.1 \%-0.4 \%, z=5.913, \quad p<0.001$, $n=1393)$, scarlet fever $(4.0[3.1-5.2] \%$ vs. $1.0 \%-2.0 \%, z=1.491$, $p<0.001, n=1389), \operatorname{RF}(0.6[0.3-1.2] \%$ vs. $0.1 \%-0.2 \%, z=3.338$, 
Table 1. Demographic Information of Obsessive Compulsive Disorder Collaborative Genetics Association Study Participants

\begin{tabular}{|c|c|c|}
\hline Characteristic & Value & $\mathrm{n}$ \\
\hline Age of proband (years) & & 140 \\
\hline Mean (SD) & $27.8(14.0)$ & \\
\hline Range & $6-82$ & \\
\hline Gender $(\% \text { of total })^{\mathrm{a}}$ & & 14 \\
\hline Male & 43.6 & \\
\hline Female & 56.4 & \\
\hline Race/ethnicity ( $\%$ of total) ${ }^{b}$ & & 139 \\
\hline Caucasian & 91.5 & \\
\hline Other ${ }^{b}$ & 8.5 & \\
\hline Age of OCD onset (years) ${ }^{\mathrm{c}}$ & & 139 \\
\hline Mean (SD) & $7.7(3.5)$ & \\
\hline Range & $1-18$ & \\
\hline YBOCS score & & 124 \\
\hline Mean (SD) & $29.1(6.3)$ & \\
\hline Range & $3-40$ & \\
\hline Psychiatric comorbidity (\% & & \\
\hline Tic disorder ${ }^{\mathrm{d}}$ & 22.4 & 6 \\
\hline Mood disorder & 64.9 & 1374 \\
\hline Anxiety disorder & 66.7 & 1361 \\
\hline $\mathrm{ADHD}$ & 15.3 & 1245 \\
\hline Eating disorder & 8.4 & 1375 \\
\hline Psychotic disorder & 0.4 & 1376 \\
\hline
\end{tabular}

${ }^{\mathrm{a}}$ Percentages represent frequencies relative to $n$ total respondents for each question.

${ }^{\mathrm{b}}$ Response choices included a mixture of race and ethnicity. Other ethnicities included Hispanic/Latin American (2.9\%) and African American $(1.5 \%)$

${ }^{c} \mathrm{Age}$ of onset is based on age at initial symptom presentation. Age at which study participants first met DSM-IV diagnostic criteria for OCD was 10.1 (3.7) years (range $1-18$ years, $n=1388$ ).

${ }^{\mathrm{d}}$ A subset of patients was not assessed for all tic disorders and has therefore been omitted from the denominator.

YBOCS, Yale-Brown Obsessive Compulsive Scale; SD, standard deviation; OCD, obsessive compulsive disorder; ADHD, attentiondeficit/hyperactivity disorder.

$p<0.001, n=1390)$, and RA $(1.1[0.6-2.0] \%$ vs. $0.2 \%-0.4 \%$, $z=3.416, p<0.001, n=949)$.

All cases of RF $(n=8 / 1390)$ were in females, yielding genderspecific prevalence estimates of $1.0[0.5-2.1] \%(n=780)$ for females and $0.0[0.0-0.5] \%(n=610)$ for males $(p=0.011$, Fisher's exact test, not significant when corrected for multiple comparisons among all conditions in Table 2). Participants with OCD onset at 8 years or younger had a higher prevalence of tic disorders compared with those with later onset (30.0 [24.5-36.1]\% vs. 18.7 [15.3$22.5] \%, n=687, p=0.001$ by Fisher's exact test), but no difference in prevalence of any immune-related comorbidity. Similarly, there was no significant effect of gender, ethnicity (Caucasian vs. other), or comorbid tic disorder on prevalence of encephalitis or meningitis, frequent ear/throat infections, scarlet fever, RF, RA, asthma, psoriasis, IBD, or the presence of at least one comorbidity.

\section{Immune-related disease prevalence in first-degree relatives}

A subset of first-degree relatives also completed a portion of the medical questionnaire $(n=1045)$. Approximately $60 \%$ had probable or definite OCD, and these first-degree relatives were on av- erage younger at the time of assessment than those without OCD $[34.9 \pm 19.2$ vs. $50.3 \pm 17.7$ years, $t(1043)=-13.974, p<0.001$, $n=1045]$. Table 3 compares prevalence of immune-related comorbidities in first-degree relatives with and without OCD for conditions with available data from at least $5 \%$ of participants in each group. Similar to OCD-affected probands, the self-reported lifetime prevalence of RF, encephalitis or meningitis, and scarlet fever was greater than expected compared with population rates. There was no difference in prevalence between OCD-affected and unaffected first-degree relatives (Table 3), although the study was insufficiently powered to detect differences in prevalence less than two-fold for each condition.

Of the 413 mothers of probands who completed medical questionnaires, frequencies of RF, scarlet fever, frequent ear/throat infections, and encephalitis/meningitis were similar to those in the overall first-degree relative group. Very few mothers completed the second section of the questionnaire regarding physician-diagnosed autoimmune and inflammatory diseases; therefore, we could not estimate prevalence of maternal SLE, MS, RA, type 1 diabetes, or psoriasis.

\section{Association of immune-related diseases and OCD symptoms}

Neither age at the time of diagnosis nor YBOCS score was related to the presence of individual comorbidities or their general categories (infectious, autoimmune/inflammatory, or any immunerelated comorbidity) (Supplementary Table S3). We next determined OCD symptom scores based on a previous factor analysis of symptoms in the YBOCS-CL (Bloch et al. 2008). Participants reporting at least one immune-related comorbidity had slightly higher scores for forbidden thoughts, cleaning, and hoarding (Supplementary Table S3). These differences were primarily driven by frequent ear or throat infections, the only condition with an increased score for cleaning-related symptoms that remained significant after adjustment for multiple comparisons [2.5 \pm 0.9 vs. $2.3 \pm 1.0, t(644)=3.183, p=0.002, n=822]$. There was no difference in YBOCS score or symptom severity based on gender.

\section{Groupings of immune-related comorbidities}

To determine whether specific immune-related comorbidities tend to group together, we assessed the relative risk of each comorbidity given the presence of another using a pairwise comparison matrix for all conditions in Table 3. Frequent throat/ear infections, scarlet fever, and RF-all potential consequences of streptococcal infection-showed significant pairwise associations (Supplementary Table S4 and Fig. 1). Moreover, asthma was associated with frequent throat/ear infections; SLE with RA; psoriasis with RA, MS, and asthma; and RF with IBD. These data identify groups of conditions with potential shared etiology and common environmental and genetic risk factors.

\section{Discussion}

This descriptive study used self-report medical questionnaires from a large cohort of patients with childhood-onset OCD to estimate the lifetime prevalence of immune-related medical comorbidities. Self-reported lifetime prevalence of encephalitis or meningitis, scarlet fever, RF, and RA was greater than expected in probands with OCD and in their OCD-affected and unaffected firstdegree relatives. Similar rates of RF, encephalitis or meningitis, and scarlet fever were identified in first-degree relatives 
Table 2. Lifetime Prevalence of Infectious and Immune-Mediated Diseases Among Obsessive Compulsive Disorder Collaborative Genetics Association Study Probands

\begin{tabular}{|c|c|c|c|c|c|c|}
\hline \multirow[b]{2}{*}{ Medical comorbidity } & \multicolumn{3}{|c|}{ Prevalence $^{\mathrm{a}}$} & \multirow[b]{2}{*}{ Population estimate (\%) } & \multicolumn{2}{|c|}{ Comparison } \\
\hline & Cases & $\%(C I)^{\mathrm{b}}$ & $\mathrm{n}$ & & $\mathrm{z}$ & $\mathrm{P}$ \\
\hline \multicolumn{7}{|l|}{ Infectious } \\
\hline Encephalitis or meningitis & 19 & $1.4(0.9-2.2)^{\mathrm{c}}$ & 1379 & $0.1-0.4$ & 5.883 & $<0.001$ \\
\hline Frequent ear/throat infections & 495 & $35.9(33.4-38.4)$ & 1381 & ND & NA & NA \\
\hline Scarlet fever & 55 & $4.0(3.1-5.2)^{\mathrm{c}}$ & 1375 & $1.0-2.0$ & 5.297 & $<0.001$ \\
\hline \multicolumn{7}{|l|}{ Autoimmune } \\
\hline Rheumatic fever & 8 & $0.6(0.3-1.2)^{\mathrm{c}}$ & 1376 & $0.1-0.2$ & 3.321 & 0.009 \\
\hline Rheumatoid arthritis & 10 & $1.1(0.6-2.0)^{\mathrm{c}}$ & 949 & $0.2-0.4$ & 3.416 & 0.006 \\
\hline SLE & 3 & $0.3(0.1-1.0)$ & 949 & $0.2-0.3$ & 0.000 & 1.000 \\
\hline Type 1 diabetes ${ }^{\mathrm{d}}$ & 5 & $0.5(0.2-1.3)$ & 951 & $0.2-0.6$ & 0.399 & 0.690 \\
\hline \multicolumn{7}{|l|}{ Atopic } \\
\hline Asthma & 164 & $17.2(14.9-19.7)$ & 953 & $11.9-14.3$ & 2.557 & 0.011 \\
\hline \multicolumn{7}{|l|}{ Inflammatory } \\
\hline Psoriasis & 21 & $2.2(1.4-3.4)$ & 951 & $2.6-3.7$ & 0.775 & 0.438 \\
\hline Ulcerative colitis & 6 & $0.6(0.3-1.4)$ & 949 & $0.4-0.8$ & 0.692 & 0.489 \\
\hline Crohn's disease & 5 & $0.5(0.2-1.3)$ & 947 & $0.4-0.8$ & 0.488 & 0.626 \\
\hline IBD & 10 & $1.1(0.6-2.0)$ & 945 & $0.8-1.3$ & 0.543 & 0.587 \\
\hline
\end{tabular}

Conditions with $95 \% \mathrm{CI}$ containing 0 were not included in this table: Sydenham's chorea $(0.1[0.0-0.5] \%, n=1381)$ and multiple sclerosis $(0.2[0.0-$ $0.8] \%, n=951)$. There were no reported cases of rheumatic heart disease.

${ }^{a}$ Prevalence determined based on $n=$ total number of respondents (denominator). There were no significant differences in prevalence based on gender when adjusted for multiple comparisons $(\alpha=0.05, n=12)$, although all eight cases of rheumatic fever were in females. Gender-specific prevalence estimates were $1.0[0.5-2.1] \%(n=780)$ for females and $0[0.0-0.5] \%(n=610)$ for males $(p=0.011$, Fisher's exact test $)$.

${ }^{\mathrm{b}} \mathrm{CI}, 95 \%$ binomial confidence interval calculated by adjusted Wald formula.

${ }^{c}$ Estimated prevalence greater than expected based on published population data. Note limited available data on scarlet fever incidence in the United

States of America; expected lifetime prevalence at age 30 was estimated assuming highest recent international rates (Supplementary Table S2).

${ }^{d}$ Estimate based on age of diabetes diagnosis at $\leq 40$ years and insulin dependence.

ND, not determined; NA, not applicable; IBD, inflammatory bowel disease; SLE, systemic lupus erythematosus.

independent of OCD status, suggesting that-if reflective of true increased prevalence-such comorbidities may represent common familial traits and genetic vulnerability rather than state markers of disease.

Given the potential for reporting bias and lack of a control group in the present study, a replication sample would aid in providing further support for these findings. Nevertheless, these data constitute the largest descriptive study of selected immune-related diseases in childhood-onset OCD and point to a need for further controlled clinical studies to understand the potential interactions between OCD and comorbid medical conditions. To date, clinical evidence addressing comorbid autoimmune and inflammatory dis- eases in patients and family members with childhood-onset OCD has largely been limited to small studies focused on the putative PANS/ PANDAS subtype (Supplementary Table S1).

Potential mechanisms for the association among immune-related comorbidities and OCD include shared genetic and environmental susceptibility, given associations between autoimmune disease in adults with OCD and their first-degree relatives (Mataix-Cols et al. 2017); maternal antibody transfer during pregnancy given increased frequency among mothers with autoimmune disorders compared with other first-degree relatives (Vincent et al. 2003), although this appears more relevant in tic disorders (Mataix-Cols et al. 2017); or exposure to dysregulated plasma cytokines (Golan

Table 3. Lifetime Prevalence of Immune-Mediated Comorbidities Among First-Degree Relatives of Obsessive Compulsive Disorder Collaborative Genetics Association Study Probands With and Without Obsessive COMPUlsive DisORDER

\begin{tabular}{|c|c|c|c|c|c|c|c|c|}
\hline \multirow[b]{2}{*}{ Comorbidity } & \multicolumn{3}{|c|}{ Prevalence in relatives with $O C D^{\mathrm{a}}$} & \multicolumn{3}{|c|}{ Prevalence in relatives without $O C D$} & \multicolumn{2}{|c|}{ Comparison } \\
\hline & Cases & $\%(C I)^{\mathrm{b}}$ & $\mathrm{n}$ & Cases & $\%(C I)^{\mathrm{b}}$ & $\mathrm{n}$ & $\chi^{2}$ & $\mathrm{P}$ \\
\hline Rheumatic fever & 8 & $1.3(0.6-2.6)^{\mathrm{c}}$ & 607 & 9 & $2.2(1.1-4.2)^{\mathrm{b}}$ & 404 & 1.203 & 0.273 \\
\hline Rheumatic heart disease & 4 & $0.7(0.2-1.7)$ & 609 & 2 & $0.5(0.0-1.9)$ & 405 & 0.002 & 0.968 \\
\hline Encephalitis or meningitis & 9 & $1.5(0.7-2.8)^{\mathrm{c}}$ & 609 & 5 & $1.2(0.4-3.0)^{\mathrm{b}}$ & 404 & 0.002 & 0.968 \\
\hline Sydenham's chorea & 1 & $0.2(0.0-1.0)$ & 611 & 0 & $0(0.0-0.8)$ & 404 & 0.028 & 0.867 \\
\hline Frequent ear or throat infections & 168 & $27.9(24.4-31.6)$ & 603 & 89 & $22.4(18.6-26.8)$ & 397 & 0.003 & 0.958 \\
\hline Scarlet fever & 23 & $3.8(2.5-5.7)^{\mathrm{c}}$ & 603 & 23 & $5.8(3.9-8.6)^{\mathrm{b}}$ & 397 & 0.021 & 0.885 \\
\hline
\end{tabular}

${ }^{a}$ Cases defined by definite or probable OCD. Prevalence determined based on $n=$ total number of respondents (denominator).

${ }^{\mathrm{b}} \mathrm{CI}, 95 \%$ binomial confidence interval calculated by adjusted Wald formula.

${ }^{c}$ Prevalence greater than expected based on published data (Supplementary Table S2).

OCD, obsessive compulsive disorder. 


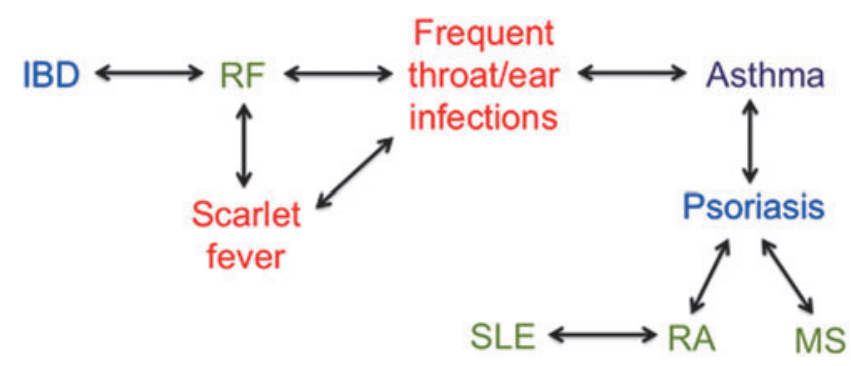

FIG. 1. Associations among immune-related comorbidities in OCD Collaborative Genetics Association Study probands with childhood-onset OCD. Significant associations described in Supplementary Table S4 are depicted by two-way arrows. Comorbidities include diseases with autoimmune (green; SLE, RA, MS), infectious (red; ear/throat infections, scarlet fever), combined autoimmune and infectious (RF), atopic (purple; asthma), and inflammatory (blue; psoriasis, IBD) etiologies, although recent data suggest significant overlap in pathophysiology and genetic predisposition among these conditions. All except for an association between IBD and rheumatic fever have been reported for the general population. IBD, inflammatory bowel disease; SLE, systemic lupus erythematosus; RA, rheumatoid arthritis; MS, multiple sclerosis; RF, rheumatic fever; OCD, obsessive compulsive disorder.

et al. 2005) leading to altered brain development. For example, previous work has also suggested a familial relationship between obsessive compulsive spectrum disorders and RF (Seixas et al. 2008), an autoimmune disease thought to arise from humoral and cellular autoreactivity following group A streptococcal (GAS) pharyngitis (Bright et al. 2016).

While the heritability of acute RF has been estimated at $60 \%$, few replicable genetic susceptibility loci have been identified (Engel et al. 2011). Other autoimmune disorders such as SLE have also been associated with increased rates of OCD (Bachen et al. 2009), and RA is associated with higher risk of concurrent mood and anxiety disorders (Nicassio 2010). Low but non-zero rates of SLE and type 1 diabetes were identified in the OCGAS cohort, both within the expected range. Higher-than-expected rates of RFshared by first-degree relatives both with and without OCDsupport the potential familial association suggested by preliminary studies. Further work that includes self-report data in healthy controls - and additional population-level epidemiological datais needed to confirm and extend these findings. One limitation of existing national registries is the lack of detailed information on clinical phenotype, which may be relevant in understanding prognosis and response to conventional therapeutic agents in these individuals.

An association with frequent streptococcal infections has led to the hypothesis that some children with OCD have impaired humoral immune function (Swedo et al. 1998; Murphy et al. 2004). Indeed, a recent survey of 908 patients with PANS concluded that immune dysfunction is "pervasive," with $53 \%$ of patients tested for some measure of immune status showing at least one abnormality, although there was no control group (Calaprice et al. 2017). In particular, 25\% reported a diagnosis of immunodeficiency, most commonly hypogammaglobulinemia, although interpretation of these data is complicated by collection of samples during possible acute infection; moreover, based on typical assay protocols the actual prevalence of specific abnormalities (e.g., low immunoglobulin G) appeared comparable to expected values
(Walker et al. 1994). There have also been preliminary reports of low IgA levels in patients with OCD compared with anxiety disorders or attention-deficit/hyperactivity disorder (Williams 2016).

While our data point to a higher-than-expected prevalence of meningitis or encephalitis (either infectious or autoimmune) as well as scarlet fever in both probands and non-OCD-affected first-degree relatives, further studies are needed to compare selfreported disease frequencies with a control group. Nevertheless, these data raise the possibility that sequelae of GAS infection are present at high rates and may be trait markers in families with a significant burden of OCD.

Moreover, our finding of increased cleaning obsessions and compulsions in patients reporting frequent ear or throat infections suggests that specific medical comorbidities - in this case, infectionsmay affect the content and severity of specific OCD symptoms. Alternatively, a patient's symptom severity may affect their perception of their medical history and reporting of illness. While there was no effect of comorbidity status on overall YBOCS score for the worst episode, other more sensitive differences in the course or expression of OCD_-including episode duration, frequency, and mean severity-were not captured in this study.

Among immune-related comorbidities, we identified several associations consistent with previously reported epidemiological data (Fig. 1): RA with SLE and psoriasis (Lin et al. 1998; AlarconSegovia et al. 2005; Naldi and Mercuri 2010), MS and asthma with psoriasis (Fang et al. 2015; Egeberg et al. 2016), and RF with scarlet fever and throat/ear infections (Soderholm et al. 2018). We also found an association between IBD and RF, consistent with preliminary evidence for shared genetic risk (Abdallah et al. 2016) and data linking IBD with other immune-mediated diseases (Halling et al. 2017).

IBD includes Crohn's disease and ulcerative colitis, two chronic inflammatory disorders of the gastrointestinal tract. A recent systematic review described high rates of anxiety and depression in patients with IBD compared with healthy controls, particularly when the disease was active; children were also at increased risk of developing psychiatric comorbidities after IBD onset (MikockaWalus et al. 2016). While there may be etiological distinctions between childhood- and adult-onset IBD, the limited number of cases in the OCGAS cohort prevented any meaningful subgroup analysis. While our data do not support an association between IBD and OCD, larger population-based studies or multisite clinical registries are required given the low population frequency of individuals with both conditions.

It remains to be determined whether altered mucosal immunity involving the oropharynx - potentially leading to increased risk for scarlet fever and RF - might be causally related to the pathogenesis of OCD or simply represent nonspecific relationships among psychiatric and medical diseases. For example, the putative associations described herein may represent shared genetic and/or environmental risks predisposing individuals to both peripheral and central inflammation with neurodevelopmental consequences, including OCD (Hanamsagar and Bilbo 2017).

Alternatively, elements of both systemic immune disease and OCD may alter physiology so as to perpetuate symptoms of each other; proposed mechanisms involve the stress response, central activity of immunomodulatory signaling molecules such as histamine (Rapanelli et al. 2017), and alterations in microbiota (Sherwin et al. 2016; Rieder et al. 2017). The experience of both acute and chronic medical symptoms such as pain may also precipitate or modify OCD symptoms. There is also growing evidence that chronic psychiatric illnesses affect the expression and severity of 
immune-related diseases, both in utero (Douros et al. 2017; Van den Bergh et al. 2017) and later in life through altered glucocorticoid and beta-adrenergic activity (Ohno 2017).

While further studies facilitated by international multicenter collaborations are needed to better understand these relationships and underlying mechanisms, the true test of causality lies in interventional clinical trials. For example, a role for prostagalandin and thromboxane synthesis is suggested by efficacy of celecoxib as an adjuvant to fluvoxamine in OCD (Shalbafan et al. 2015), and other therapies that modulate mucosal immunity may also prove to be of benefit. Trials aimed at determining the effects of probiotic treatment in adults with OCD (NCT02334644) and of ibuprofen on functional magnetic resonance imaging activation patterns in the amygdala (NCT02507219) are currently ongoing.

Limitations of this study include potential bias associated with the retrospective nature of self-report in the OCGAS study (particularly for scarlet fever and RF, which require specific diagnostic criteria) and the absence of a control group. If present, however, the recollection bias appears to have affected probands and relatives for overlapping conditions (encephalitis or meningitis, scarlet fever, and RF), making it less likely that it is a random occurrence. Moreover, previous data suggest that the presence of an autoimmune disease based on self-report cannot be verified by checking medical records in up to $30 \%$ of cases (Broadley et al. 2000), and verification was not performed in this study. Similar error rates may be present in this study; although no data are available on recall bias specifically in patients with OCD, this population may overestimate personal risk of disease.

While we have attempted to thoroughly review available data and provide a broad estimate of population ranges, in some casesparticularly for nonreportable infectious diseases-these data are not available. Regional, temporal, and ethnic variations in prevalence among studies also limit the utility of calculated population rates in the context of a predominantly Caucasian population with a broad age range. In addition, the OCGAS medical questionnaire was limited to selected conditions and did not provide a comprehensive list of infectious, autoimmune, or inflammatory comorbidities. While conditions such as autoimmune thyroid diseases that are often difficult for patients to distinguish from nonautoimmune thyroid conditions without knowledge of laboratory testing were not included in this study, other categories such as encephalitis/meningitis were ambiguous with respect to etiology; although the vast majority of cases of meningitis are due to infection, approximately half of encephalitis cases may be autoimmune (Dubey et al. 2018).

Finally, given the relative rarity of autoimmune conditions in both the general population and in children with OCD, our data are limited by small sample sizes and low power to detect small differences between subgroups, including OCD-affected and nonaffected first-degree relatives. Nevertheless, our study is the first to carefully consider published population rates and is the largest descriptive study of immune-related comorbidities in childhoodonset OCD. These limitations, most present in previous smaller studies, highlight the need for further data in both general OCD and PANS/PANDAS populations that includes healthy controls together with means of verifying comorbidity diagnoses.

It is unclear whether our findings are specific to OCD or common among multiple psychiatric disorders. Other studies have provided circumstantial evidence for an association between immune-related disorders-including atopic disease and autoimmunity-and psychiatric comorbidities, including depression, schizophrenia, autism spectrum disorder, and other developmental disorders (Sweeten et al. 2003; Croen et al. 2005; Mouridsen et al. 2007; Gesundheit et al. 2013; Postal and Appenzeller 2015; Schans et al. 2017). Recent data suggest a link between stress-related disorders and subsequent autoimmune disease (Song et al. 2018). Moreover, other medical comorbidities, including migraines and respiratory diseases, are known to be more common among adults with OCD (Witthauer et al. 2014). Implementation of standardized medical comorbidity questionnaires across multiple pediatric psychiatric clinics may aid in determining whether particular comorbidities are associated with increased risk of specific psychiatric symptoms or diagnoses.

\section{Conclusions}

Taken together, these data raise the possibility of an association between childhood-onset OCD and central nervous system infection or inflammation together with poststreptococcal autoimmunity. Delineation of clinical patterns of disease aggregation may provide mechanistic insight into this disease. Further multicenter controlled studies - in addition to larger population-based studiesare needed to characterize medical comorbidities in pediatric OCD and may aid in the development of therapeutic strategies targeting the immune response.

\section{Clinical Significance}

Existing studies of immune-related comorbidities in childhoodonset OCD are limited by small sample sizes and restriction to assessment of PANS/PANDAS subtypes. This is the largest study to date describing immune-related comorbidities in a general population with childhood-onset OCD and points to high rates of certain inflammatory and infectious conditions in both affected individuals and their first-degree relatives. Our data are consistent with other recent studies suggesting that the increased prevalence of immune-related comorbidities may not be unique to PANS/ PANDAS and provide an impetus for additional carefully designed research studies.

These findings also point to several considerations relevant to current clinical practice. A thorough medical history, including specific questions regarding chronic immune-related conditions as well as acute triggers such as infections should be considered in the diagnostic assessment of all children presenting with OCD symptoms. If identified, the impact of these medical comorbidities on OCD-related symptoms and functional status requires further assessment. Appropriate psychoeducation may include discussion of the multiple factors contributing to OCD risk, onset, and progression, including potential etiological links between the immune system and the brain that have also been described in other psychiatric disorders but about which our knowledge remains limited.

Clinical trials of adjunctive anti-inflammatory drugs, such as NSAIDS, may also be warranted in children with treatmentrefractory OCD symptoms. Ultimately, further work is required to better understand the etiologic and prognostic implications of the associations identified in this study, with the goal of improving our understanding of OCD pathogenesis and facilitating the development of adjunctive immune-modulating therapeutic strategies.

\section{Acknowledgments}

The authors thank Laura Belscher and Sarah Lin (University of British Columbia) for assistance with REDCap data management, Fern Jaspers-Fayer (University of British Columbia) for initial consolidation of electronic and paper charts, and Boris Kuzeljevic (BC Children's Hospital) for advice on statistical methods. 


\section{Disclosures}

No competing financial interests exist.

\section{Supplementary Material}

Supplementary Data

Supplementary Table S1

Supplementary Table S2

Supplementary Table S3

Supplementary Table S4

\section{References}

Abdallah AM, Al-Mazroea AH, Al-Harbi WN, Al-Harbi NA, Eldardear AE, Almohammadi Y, Al-Harbi KM: Impact of MIF gene promoter variations on risk of rheumatic heart disease and its age of onset in Saudi Arabian patients. Front Immunol 7:98, 2016.

Agresti A, Coull BA: Approximate is better than 'exact' for interval estimation of binomial proportions. Am Stat 52:119-126, 1998.

Alarcon-Segovia D, Alarcon-Riquelme ME, Cardiel MH, Caeiro F, Massardo L, Villa AR, Pons-Estel BA, Grupo Latinoamericano de Estudio del Lupus E: Familial aggregation of systemic lupus erythematosus, rheumatoid arthritis, and other autoimmune diseases in 1,177 lupus patients from the GLADEL cohort. Arthritis Rheum 52:1138-1147, 2005.

American Psychiatric Association: Diagnostic and Statistical Manual of Mental Disorders, 4th ed. Washington, DC: American Psychiatric Association; 1994.

Attwells S, Setiawan E, Wilson AA, Rusjan PM, Mizrahi R, Miler L, Xu C, Richter MA, Kahn A, Kish SJ, Houle S, Ravindran L, Meyer $\mathrm{JH}$ : Inflammation in the neurocircuitry of obsessive-compulsive disorder. JAMA Psychiatry 74:833-840, 2017.

Bachen EA, Chesney MA, Criswell LA: Prevalence of mood and anxiety disorders in women with systemic lupus erythematosus. Arthritis Rheum 61:822-829, 2009.

Benjamini Y, Hochberg Y: Controlling the false discovery rate: A practical and powerful approach to multiple testing. J R Stat Soc Ser B 57:289-300, 1995.

Bloch MH, Landeros-Weisenberger A, Rosario MC, Pittenger C, Leckman JF: Meta-analysis of the symptom structure of obsessivecompulsive disorder. Am J Psychiatry 165:1532-1542, 2008.

Bright PD, Mayosi BM, Martin WJ: An immunological perspective on rheumatic heart disease pathogenesis: More questions than answers. Heart 102:1527-1532, 2016.

Broadley SA, Deans J, Sawcer SJ, Clayton D, Compston DA: Autoimmune disease in first-degree relatives of patients with multiple sclerosis. A UK survey. Brain 123 (Pt 6):1102-1111, 2000.

Calaprice D, Tona J, Parker-Athill EC, Murphy TK: A survey of pediatric acute-onset neuropsychiatric syndrome characteristics and course. J Child Adolesc Psychopharmacol 27:607-618, 2017.

Chang K, Frankovich J, Cooperstock M, Cunningham MW, Latimer ME, Murphy TK, Pasternack M, Thienemann M, Williams K, Walter J, Swedo SE, Consortium PC: Clinical evaluation of youth with pediatric acute-onset neuropsychiatric syndrome (PANS): Recommendations from the 2013 PANS consensus conference. J Child Adolesc Psychopharmacol 25:3-13, 2015.

Chen D, Bienvenu OJ, Krasnow J, Wang Y, Grados MA, Cullen B, Goes FS, Maher B, Greenberg BD, McLaughlin NC, Rasmussen SA, Fyer AJ, Knowles JA, McCracken JT, Piacentini J, Geller D, Pauls DL, Stewart SE, Murphy DL, Shugart Y-Y, Riddle MA,
Nestadt G, Samuels J: Parental bonding and hoarding in obsessivecompulsive disorder. Compr Psychiatry 73:43-52, 2017.

Croen LA, Grether JK, Yoshida CK, Odouli R, Van de Water J: Maternal autoimmune diseases, asthma and allergies, and childhood autism spectrum disorders: A case-control study. Arch Pediatr Adolesc Med 159:151-157, 2005.

Dale RC, Heyman I, Giovannoni G, Church AW: Incidence of antibrain antibodies in children with obsessive-compulsive disorder. $\mathrm{Br}$ J Psychiatry 187:314-319, 2005.

den Braber A, Zilhao NR, Fedko IO, Hottenga JJ, Pool R, Smit DJ, Cath DC, Boomsma DI: Obsessive-compulsive symptoms in a large population-based twin-family sample are predicted by clinically based polygenic scores and by genome-wide SNPs. Transl Psychiatry 6:e731, 2016.

Douros K, Moustaki M, Tsabouri S, Papadopoulou A, Papadopoulos $\mathrm{M}$, Priftis KN: Prenatal maternal stress and the risk of asthma in children. Front Pediatr 5:202, 2017.

Dubey D, Pittock SJ, Kelly CR, McKeon A, Lopez-Chiriboga AS, Lennon VA, Gadoth A, Smith CY, Bryant SC, Klein CJ, Aksamit AJ, Toledano M, Boeve BF, Tillema JM, Flanagan EP: Autoimmune encephalitis epidemiology and a comparison to infectious encephalitis. Ann Neurol 83:166-177, 2018.

Egeberg A, Mallbris L, Gislason GH, Skov L, Hansen PR: Risk of multiple sclerosis in patients with psoriasis: A Danish nationwide cohort study. J Invest Dermatol 136:93-98, 2016.

Engel ME, Stander R, Vogel J, Adeyemo AA, Mayosi BM: Genetic susceptibility to acute rheumatic fever: A systematic review and meta-analysis of twin studies. PLoS One 6:e25326, 2011.

Fang HY, Liao WC, Lin CL, Chen CH, Kao CH: Association between psoriasis and asthma: A population-based retrospective cohort analysis. Br J Dermatol 172:1066-1071, 2015.

First MB, Spitzer RL, Gibbon M, Williams JBW: Structured Clinical Interview for DSM-IV-TR Axis I Disorders, Research Version, Patient Edition. New York, Biometrisc Research, New York State Psychiatric Institute, 2002.

Frankovich J, Thienemann M, Pearlstein J, Crable A, Brown K, Chang $\mathrm{K}$ : Multidisciplinary clinic dedicated to treating youth with pediatric acute-onset neuropsychiatric syndrome: Presenting characteristics of the first 47 consecutive patients. J Child Adolesc Psychopharmacol 25:38-47, 2015.

Gesundheit B, Rosenzweig JP, Naor D, Lerer B, Zachor DA, Prochazka V, Melamed M, Kristt DA, Steinberg A, Shulman C, Hwang P, Koren G, Walfisch A, Passweg JR, Snowden JA, Tamouza R, Leboyer M, Farge-Bancel D, Ashwood P: Immunological and autoimmune considerations of autism spectrum disorders. J Autoimmun 44:1-7, 2013.

Golan HM, Lev V, Hallak M, Sorokin Y, Huleihel M: Specific neurodevelopmental damage in mice offspring following maternal inflammation during pregnancy. Neuropharmacology 48:903-917, 2005.

Goodman WK, Price LH, Rasmussen SA, Mazure C, Fleischmann RL, Hill CL, Heninger GR, Charney DS: The Yale-Brown obsessive compulsive scale. I. Development, use, and reliability. Arch Gen Psychiatry 46:1006-1011, 1989.

Gray SM, Bloch MH: Systematic review of proinflammatory cytokines in obsessive-compulsive disorder. Curr Psychiatry Rep 14: 220-228, 2012.

Halling ML, Kjeldsen J, Knudsen T, Nielsen J, Hansen LK: Patients with inflammatory bowel disease have increased risk of autoimmune and inflammatory diseases. World J Gastroenterol 23:61376146, 2017.

Hanamsagar R, Bilbo SD: Environment matters: Microglia function and dysfunction in a changing world. Curr Opin Neurobiol 47:146$155,2017$. 
Hollander E, Doernberg E, Shavitt R, Waterman RJ, Soreni N, Veltman DJ, Sahakian BJ, Fineberg NA: The cost and impact of compulsivity: A research perspective. Eur Neuropsychopharmacol 26:800-809, 2016.

Hounie AG, Pauls DL, do Rosario-Campos MC, Mercadante MT, Diniz JB, De Mathis MA, De Mathis ME, Chacon P, Shavitt RG, Curi M, Guilherme L, Miguel EC: Obsessive-compulsive spectrum disorders and rheumatic fever: A family study. Biol Psychiatry 61: 266-272, 2007.

International Obsessive Compulsive Disorder Foundation Genetics Collaborative (IOCDF-GC) and OCD Collaborative Genetics Association Studies (OCGAS): Revealing the complex genetic architecture of obsessive-compulsive disorder using meta-analysis. Mol Psychiatry 23:1181-1188, 2018.

Jaspers-Fayer F, Han SHJ, Chan E, McKenney K, Simpson A, Boyle A, Ellwyn R, Stewart SE: Prevalence of acute-onset subtypes in pediatric obsessive-compulsive disorder. J Child Adolesc Psychopharmacol 27:332-341, 2017.

Kawikova I, Grady BP, Tobiasova Z, Zhang Y, Vojdani A, Katsovich L, Richmand BJ, Park TW, Bothwell AL, Leckman JF: Children with Tourette's syndrome may suffer immunoglobulin A dysgammaglobulinemia: Preliminary report. Biol Psychiatry 67:679-683, 2010.

Levene H: Robust tests for equality of variances. In: Contributions to Probability and Statistics: Essays in Honor of Harold Hotelling. Edited by Olkin I, Ghurye SG, Hoeffding W, Madow WG, Mann HB. Palo Alto, CA, Stanford University Press, 1960, pp. 278-292.

Lin JP, Cash JM, Doyle SZ, Peden S, Kanik K, Amos CI, Bale SJ, Wilder RL: Familial clustering of rheumatoid arthritis with other autoimmune diseases. Hum Genet 103:475-482, 1998.

Macpherson AJ, Geuking MB, McCoy KD: Immunoglobulin A: A bridge between innate and adaptive immunity. Curr Opin Gastroenterol 27:529-533, 2011.

Mancebo MC, Boisseau CL, Garnaat SL, Eisen JL, Greenberg BD, Sibrava NJ, Stout RL, Rasmussen SA: Long-term course of pediatric obsessive-compulsive disorder: 3 Years of prospective followup. Compr Psychiatry 55:1498-1504, 2014.

Mataix-Cols D, Boman M, Monzani B, Ruck C, Serlachius E, Langstrom N, Lichtenstein P: Population-based, multigenerational family clustering study of obsessive-compulsive disorder. JAMA Psychiatry 70:709-717, 2013.

Mataix-Cols D, Frans E, Perez-Vigil A, Kuja-Halkola R, Gromark C, Isomura K, Fernandez de la Cruz L, Serlachius E, Leckman JF, Crowley JJ, Ruck C, Almqvist C, Lichtenstein P, Larsson H: A total-population multigenerational family clustering study of autoimmune diseases in obsessive-compulsive disorder and Tourette's/chronic tic disorders. Mol Psychiatry 23:1652-1658, 2018.

Mattheisen M, Samuels JF, Wang Y, Greenberg BD, Fyer AJ, McCracken JT, Geller DA, Murphy DL, Knowles JA, Grados MA, Riddle MA, Rasmussen SA, McLaughlin NC, Nurmi EL, Askland KD, Qin HD, Cullen BA, Piacentini J, Pauls DL, Bienvenu OJ, Stewart SE, Liang KY, Goes FS, Maher B, Pulver AE, Shugart YY, Valle D, Lange C, Nestadt G: Genome-wide association study in obsessive-compulsive disorder: Results from the OCGAS. Mol Psychiatry 20:337-344, 2015.

Mikocka-Walus A, Knowles SR, Keefer L, Graff L: Controversies revisited: A systematic review of the comorbidity of depression and anxiety with inflammatory bowel diseases. Inflamm Bowel Dis 22: 752-762, 2016.

Mitchell RH, Goldstein BI: Inflammation in children and adolescents with neuropsychiatric disorders: A systematic review. J Am Acad Child Adolesc Psychiatry 53:274-296, 2014.

Morer A, Lazaro L, Sabater L, Massana J, Castro J, Graus F: Antineuronal antibodies in a group of children with obsessive- compulsive disorder and Tourette syndrome. J Psychiatr Res 42:6468, 2008.

Mouridsen SE, Rich B, Isager T, Nedergaard NJ: Autoimmune diseases in parents of children with infantile autism: A case-control study. Dev Med Child Neurol 49:429-432, 2007.

Murphy TK, Sajid M, Soto O, Shapira N, Edge P, Yang M, Lewis MH, Goodman WK: Detecting pediatric autoimmune neuropsychiatric disorders associated with streptococcus in children with obsessive-compulsive disorder and tics. Biol Psychiatry 55:61-68, 2004.

Murphy TK, Storch EA, Turner A, Reid JM, Tan J, Lewin AB: Maternal history of autoimmune disease in children presenting with tics and/or obsessive-compulsive disorder. J Neuroimmunol 229: 243-247, 2010.

Naldi L, Mercuri SR: Epidemiology of comorbidities in psoriasis. Dermatol Ther 23:114-118, 2010.

Nestadt G, Samuels J, Riddle M, Bienvenu OJ, 3rd, Liang KY, LaBuda M, Walkup J, Grados M, Hoehn-Saric R: A family study of obsessive-compulsive disorder. Arch Gen Psychiatry 57:358-363, 2000.

Nicassio PM: Arthritis and psychiatric disorders: Disentangling the relationship. J Psychosom Res 68:183-185, 2010.

Ohno I: Neuropsychiatry phenotype in asthma: Psychological stressinduced alterations of the neuroendocrine-immune system in allergic airway inflammation. Allergol Int 66S:S2-S8, 2017.

Orlovska S, Vestergaard $\mathrm{CH}$, Bech $\mathrm{BH}$, Nordentoft M, Vestergaard M, Benros ME: Association of streptococcal throat infection with mental disorders: Testing key aspects of the PANDAS hypothesis in a nationwide study. JAMA Psychiatry 74:740-746, 2017.

Perez-Vigil A, Fernandez de la Cruz L, Brander G, Isomura K, Gromark C, Mataix-Cols D: The link between autoimmune diseases and obsessive-compulsive and tic disorders: A systematic review. Neurosci Biobehav Rev 71:542-562, 2016.

Postal M, Appenzeller S: The importance of cytokines and autoantibodies in depression. Autoimmun Rev 14:30-35, 2015.

Rao NP, Venkatasubramanian G, Ravi V, Kalmady S, Cherian A, Yc JR: Plasma cytokine abnormalities in drug-naive, comorbidity-free obsessive-compulsive disorder. Psychiatry Res 229:949-952, 2015.

Rapanelli M, Frick L, Pogorelov V, Ohtsu H, Bito H, Pittenger C: Histamine H3R receptor activation in the dorsal striatum triggers stereotypies in a mouse model of tic disorders. Transl Psychiatry 7: e1013, 2017.

Rieder R, Wisniewski PJ, Alderman BL, Campbell SC: Microbes and mental health: A review. Brain Behav Immun 66:9-17, 2017.

Samuels JF, Riddle MA, Greenberg BD, Fyer AJ, McCracken JT, Rauch SL, Murphy DL, Grados MA, Pinto A, Knowles JA, Piacentini J, Cannistraro PA, Cullen B, Bienvenu OJ, 3rd, Rasmussen SA, Pauls DL, Willour VL, Shugart YY, Liang KY, Hoehn-Saric R, Nestadt G: The OCD collaborative genetics study: Methods and sample description. Am J Med Genet B Neuropsychiatr Genet 141B:201-207, 2006.

Schans JV, Cicek R, de Vries TW, Hak E, Hoekstra PJ: Association of atopic diseases and attention-deficit/hyperactivity disorder: A systematic review and meta-analyses. Neurosci Biobehav Rev 74:139148, 2017.

Seixas AA, Hounie AG, Fossaluza V, Curi M, Alvarenga PG, De Mathis MA, De Mathis ME, Vallada H, Pauls D, de Braganca Pereira CA, Miguel EC: Anxiety disorders and rheumatic fever: Is there an association? CNS Spectr 13:1039-1046, 2008.

Shalbafan M, Mohammadinejad P, Shariat SV, Alavi K, Zeinoddini A, Salehi M, Askari N, Akhondzadeh S: Celecoxib as an adjuvant to fluvoxamine in moderate to severe obsessive-compulsive disorder: A double-blind, placebo-controlled, randomized trial. Pharmacopsychiatry 48:136-140, 2015. 
Sherwin E, Sandhu KV, Dinan TG, Cryan JF: May the force be with you: The light and dark sides of the microbiota-gut-brain axis in neuropsychiatry. CNS Drugs 30:1019-1041, 2016.

Simsek S, Yuksel T, Cim A, Kaya S: Serum cytokine profiles of children with obsessive-compulsive disorder shows the evidence of autoimmunity. Int J Neuropsychopharmacol 19:pii:pyw027, 2016.

Slattery MJ, Dubbert BK, Allen AJ, Leonard HL, Swedo SE, Gourley MF: Prevalence of obsessive-compulsive disorder in patients with systemic lupus erythematosus. J Clin Psychiatry 65:301-306, 2004.

Soderholm AT, Barnett TC, Sweet MJ, Walker MJ: Group A streptococcal pharyngitis: Immune responses involved in bacterial clearance and GAS-associated immunopathologies. J Leukoc Biol 103:193-213, 2018.

Song H, Fang F, Tomasson G, Arnberg FK, Mataix-Cols D, Fernandez de la Cruz L, Almqvist C, Fall K, Valdimarsdottir UA: Association of stress-related disorders with subsequent autoimmune disease. JAMA 319:2388-2400, 2018.

Stagi S, Rigante D, Lepri G, Bertini F, Matucci-Cerinic M, Falcini F: Evaluation of autoimmune phenomena in patients with pediatric autoimmune neuropsychiatric disorders associated with streptococcal infections (PANDAS). Autoimmun Rev 13:1236-1240, 2014.

Stewart SE, Geller DA, Jenike M, Pauls D, Shaw D, Mullin B, Faraone SV: Long-term outcome of pediatric obsessive-compulsive disorder: A meta-analysis and qualitative review of the literature. Acta Psychiatr Scand 110:4-13, 2004.

Stewart SE, Yu D, Scharf JM, Neale BM, Fagerness JA, Mathews CA, Arnold PD, Evans PD, Gamazon ER, Davis LK, Osiecki L, McGrath L, Haddad S, Crane J, Hezel D, Illman C, Mayerfeld C, Konkashbaev A, Liu C, Pluzhnikov A, Tikhomirov A, Edlund CK, Rauch SL, Moessner R, Falkai P, Maier W, Ruhrmann S, Grabe HJ, Lennertz L, Wagner M, Bellodi L, Cavallini MC, Richter MA, Cook EH, Jr., Kennedy JL, Rosenberg D, Stein DJ, Hemmings SM, Lochner C, Azzam A, Chavira DA, Fournier E, Garrido H, Sheppard B, Umana P, Murphy DL, Wendland JR, VeenstraVanderWeele J, Denys D, Blom R, Deforce D, Van Nieuwerburgh F, Westenberg HG, Walitza S, Egberts K, Renner T, Miguel EC, Cappi C, Hounie AG, Conceicao do Rosario M, Sampaio AS, Vallada H, Nicolini H, Lanzagorta N, Camarena B, Delorme R, Leboyer M, Pato CN, Pato MT, Voyiaziakis E, Heutink P, Cath DC, Posthuma D, Smit JH, Samuels J, Bienvenu OJ, Cullen B, Fyer AJ, Grados MA, Greenberg BD, McCracken JT, Riddle MA, Wang Y, Coric V, Leckman JF, Bloch M, Pittenger C, Eapen V, Black DW, Ophoff RA, Strengman E, Cusi D, Turiel M, Frau F, Macciardi F, Gibbs JR, Cookson MR, Singleton A, North American Brain Expression C, Hardy J, Database UKBE, Crenshaw AT, Parkin MA, Mirel DB, Conti DV, Purcell S, Nestadt G, Hanna GL, Jenike MA, Knowles JA, Cox N, Pauls DL: Genome-wide association study of obsessive-compulsive disorder. Mol Psychiatry 18:788-798, 2013.

Swedo SE, Leonard HL, Garvey M, Mittleman B, Allen AJ, Perlmutter S, Lougee L, Dow S, Zamkoff J, Dubbert BK: Pediatric autoimmune neuropsychiatric disorders associated with strepto- coccal infections: Clinical description of the first 50 cases. Am J Psychiatry 155:264-271, 1998.

Sweeten TL, Bowyer SL, Posey DJ, Halberstadt GM, McDougle CJ: Increased prevalence of familial autoimmunity in probands with pervasive developmental disorders. Pediatrics 112:e420, 2003.

Taylor S: Molecular genetics of obsessive-compulsive disorder: A comprehensive meta-analysis of genetic association studies. Mol Psychiatry 18:799-805, 2013.

Van den Bergh BRH, van den Heuvel MI, Lahti M, Braeken M, de Rooij SR, Entringer S, Hoyer D, Roseboom T, Raikkonen K, King S, Schwab M: Prenatal developmental origins of behavior and mental health: The influence of maternal stress in pregnancy. Neurosci Biobehav Rev [Epub ahead of print]; DOI: 10.1016/ j.neubiorev.2017.07.003, 2017.

Vincent A, Dalton P, Clover L, Palace J, Lang B: Antibodies to neuronal targets in neurological and psychiatric diseases. Ann N Y Acad Sci 992:48-55, 2003.

Walker AM, Kemp AS, Hill DJ, Shelton MJ: Features of transient hypogammaglobulinaemia in infants screened for immunological abnormalities. Arch Dis Child 70:183-186, 1994.

Welch BL: The generalisation of student's problems when several different population variances are involved. Biometrika 34:28-35, 1947.

Williams KA: Abstract. IgA deficiency is associated with pediatric obsessive compulsive disorder. Boston (MA), Clinical Immunology Society Annual Meeting, April 14-17, 2016.

Williams KA, Swedo SE: Post-infectious autoimmune disorders: Sydenham's chorea, PANDAS and beyond. Brain Res 1617:144154, 2015.

Witthauer C, A TG, Meyer AH, Lieb R: Physical diseases among persons with obsessive compulsive symptoms and disorder: A general population study. Soc Psychiatry Psychiatr Epidemiol 49: 2013-2022, 2014

Yuce M, Guner SN, Karabekiroglu K, Baykal S, Kilic M, Sancak R, Karabekiroglu A: Association of Tourette syndrome and obsessivecompulsive disorder with allergic diseases in children and adolescents: A preliminary study. Eur Rev Med Pharmacol Sci 18:303-310, 2014.

Address correspondence to: S. Evelyn Stewart, MD Department of Psychiatry Faculty of Medicine British Columbia Children's Hospital University of British Columbia Room A3-121, 950 West 28th Avenue Vancouver, BC V5Z $4 \mathrm{H} 4$

Canada

E-mail: evelyn.stewart@ubc.ca 